\title{
3 Being, being human, becoming beyond human
}

\author{
Timothy Carroll and Aaron Parkhurst
}

The London-based New Scientist Magazine has been publishing popular science and technology news since 1956. Each year it holds a large fourday conference in London, called 'New Scientist Live,' hosting talks and exhibitions from many of Europe's leading innovators and scientists, and attracting tens of thousands of visitors. The exhibition and speaker's space is divided into five main stage areas: Cosmos, Earth, Humans, Technology, and Engineering. While these categories have always overlapped to varying degrees, their distinctions are increasingly becoming blurred. In 2018, a talk on 'Boosting your brain with electricity and magnets' on the Humans stage was delivered simultaneously with a talk on 'Building bionic people' on the Engineering stage, as well as two talks titled 'The post-human future' and 'Our cyborg future' on the Technology stage. One of the implications of this overlap, and an intellectual challenge for scholars in these disciplines, is that the material form of the human body and external material forms of engineering and technology are increasingly imbricated.

This imbrication of the body and manufactured forms invites new biosocial approaches to investigating the role of materials within the sociality of the body. The body has, to varying degrees, always been manipulated and 'made.' The human relation to external technology, and the dynamism within the human-plus-external artefact (what we abbreviate as human-plus), is most important, not on the morphological level of the body's form, but on the technological level of the human's performative capacity. New human-plus designs, and morphological adaptations to the human body, create new forms of sociality. This is true across genres of artefacts, from fashion (Phillips 2005) to medical devices (e.g. Arteaga 2019) to body modifications in initiation practices (e.g. Ackley 2019). Such morphological adaptations to the body have clear health implications, and the design of the human-plus configurations rests upon socially defined notions of what constitutes 'therapy,' and is thus a means of restoring a 'natural' state versus what is 'enhancement,' and therefore is aimed at achieving something greater or new. The ideology of design intention is, therefore, an important aspect of how external objects are brought into orchestration with/in the body. As such, methodological approaches that 
investigate 'medical materialities' - that are looking at how 'the physical, the biological, the medical, the material, the social, [and] the symbolic are held together within a given context of care provision, well-being, and health intervention' (Carroll and Parkhurst 2019: 13) - are needed to push for an analytical model that allows for an understanding of the wide social implications and constitutions of human-plus hybridity.

The broad comparative method of anthropology - bound as it is in the ethnographic present - was expanded in the early theoretical framing of material culture studies to 'emphasize an approach that combined the study of both contemporary and past non-literate cultures from the point of view of the material record' (Rowlands 1983: 15). Peter Ucko, in his analysis of penis sheaths, frames this, saying the 'one thing which distinguishes the study of material culture from most other aspects of anthropological investigation $[\ldots]$ is that its data are manufactured objects, the result of some technological process' (1969: 29). In this view, the benefit of material culture within anthropology was that objects endured through time, allowing a synchronic analysis of cultural artefacts and their social phenomena. Objects could be revisited and used to revisit old questions with new analytical and scientific advancements. In this vein, the technology (in a broad sense) of one society at a given point in time may be used as a place of investigation and comparison with that of another society, no matter the time period or diachronic relation (Radcliffe-Brown or Morgan).

In the face of human hybridity, and the regular imbrication of the human body with manufactured material forms, the methodological investigation of material technology, following Ucko, should be extended into other domains of (post)human practices. While Ucko focused on the morphological differences of penis sheaths, we take his comparative approach to the body and its relation to external artefacts as a model to expand the material analysis from the form of the object into its transformative capacity of aspirational becoming, which informs social practice. This comparison shifts the focus from the morphology of the technology to the properties, affordances, and potentialities of the technology. The properties of technology - such as the opacity of a glass lens in a telescope - shape the possible kind of knowledge gained via, and social relations around, that object (Ihde 1998). Similarly, the affordances of an object - such as a chair to support a sitter - result from the relational complement between the object and its pair - as exhibited in a sitter's affordance to sit (Gibson 1979). These two levels of pre-social and social discursiveness give rise to any range of potential directions of social phenomena, some anticipated and designed, some that may 'torque' in excess (Pinney 2005), into unexpected directions. However, while the actual outcome of a material may be different from the design intention (see, for example the three 'relational functions' of technical objects as discussed by Coupaye, Chapter 4), the social anticipation of an object is nonetheless inscribed within the material form. It is on this level that we propose to compare a series of otherwise wholly unrelated case studies that, nevertheless, resonate with each 
other in terms of the aspirational anticipation of becoming, in some fashion, more than human.

We address the human desire to become more than human by examining two problematics, framed over three sets of case studies. The first two case studies drive at the problem of nature, religion, and the contemporary posthumanist desire to replace or become gods. The third set of case studies problematises the exceptionalism of the twenty-first-century drive towards post-humanism by comparing the use of new and emerging cybernetic technology with ritual magico-religious technological forms that have endured through the centuries.

\section{The 'cyborg' as post-human}

The imbrication of the human body and material forms of engineering and technology is an observation that has been given some attention in Science and Technology Studies (STS) and anthropology in recent years. (See, for example, Downey and Dumit 1997; Ott, Serline, and Mihm 2002; Suchman 2007.) Many drivers of these human-plus forms borrow the term 'post-human' as an explanatory identity, an ideal for the future, or simply as an inevitable consequence of the 'figural excess' (Pinney 2005) of exponential technology. Popular discourse on medical and 'enhancement' technology often creates and reinforces links between the post-human figure and that of the 'super-human.' For example, one exhibition at 'The New Scientist Live' demonstrates new prosthetic technology to replace human limbs, with an impressive range of motion and articulations. Others show emerging research in artificial brain material for cognitive 'enhancement.' The exhibitions are not sci-fi fantasy but rather are designed to be advertisements for international industry. They attract visitors with promotional images of classical comic book superheroes, with capes and costumes, arms stretched forward in mid-flight. The images are common visual metaphors for the technology being displayed.

As Lakoff and Johnson have famously theorised, common discourse is rife with metaphors that transform the way in which people think and engage with the world around them (1980). Emily Martin, in her work on fertility treatment, highlights how these metaphors impact upon the human body, especially as they are employed within the language of biomedicine (1998, 2006). Her work shows how the generative power at play between cultures of medicine and technology and the societies in which they are embedded flows both ways. In this regard, blurring the lines between the human body, technology - in a wider sense of a technical object (cf. Coupaye this volume) and engineering also blurs the line between that which is designed to 'fix' the body (i.e., therapy), and that which is designed to 'further' the body (i.e., enhancement). The 'cyborg,' as both an ethnographic object and as an analytic, purposefully blurs these distinctions. Originally coined by Clynes and Kline (1960), the term was proposed simply to describe the type of cybernetic partnerships with the human body that would be necessary to live in 
environments harmful or impossible for normative bodily capacity. In recent years, however, it has become part and parcel of a desire for the 'post-human.' It is a way of thinking about technology and engineering, not as something separate from one's 'self,' but rather as a hybrid from which worlds are formed and performed. It is purposefully 'more-than-human.'

This emphasis on hybridity is not without its contradictions. In her 'cyborg manifesto,' Donna Haraway borrowed the concept of the cyborg to emphasise her rejection of binaries and boundaries ([1985]2000). There was, ultimately, little in her analysis of material technology. The cyborg, as presented in Haraway's work, is a device to illustrate a postmodern critique of nature/ culture divides and, exemplifying a postmodern feminist perspective, it is a rejection of sex/gender in similar terms. She writes:

The cyborg is a creature in a post-gender world; it has no truck with bisexuality, pre-Oedipal symbiosis, unalienated labour, or other seductions to organic wholeness through a final appropriation of all the powers of the parts into a higher unity.

([1985]2000: 51)

However, despite Haraway's emphasis on liberation and the rejection of traditional power structures, the concept of the cyborg plays upon hybridity to make claims of gestalt. This 'higher unity' is simultaneously abortive and generative, and many technologists reify and deploy the unification of binarisms Haraway attempted to overcome as evidence for post-humanism. Liberation through cyborgian identity, and the potential for technology to afford transcendence is, for many of Parkhurst's research partners, entwined. In this way, attempts to overcome nature/culture divides through a renunciation of, say, sex and gender, often ironically betray the postmodern mission, and instead reinforce the nature/culture divide through an emphasis on the hybridity of the postmodern body as a form of transcendence - something more than the 'natural' human.

The human's relationship with technology is often fraught with these contradictions. Some prominent British technologists who praise the cyborg for its capacity for liberation simultaneously envision and celebrate a future rife with inequality. They view the capacity of technology as permission for a mastery over others (Warwick 2003; Parkhurst 2012). They speak publicly, and often, of the Übermensch, Nietzsche's answer to those structures that he envisioned limiting humanity's potential, specifically religion. Kevin Warwick, a leading figure in British cybernetics, and author of I, Cyborg (2004), uses the term Übermensch, not in the pop-cultural sense of a superhero, but in its original Nietzschean sense. In Nietzsche's words, it will be the 'new, vast aristocracy based on the most severe self-discipline, in which the will of philosophical men of power and artist-tyrants will be stamped upon thousands of years [...] working as artists upon man himself!' (1927: 960). This selfdiscipline is envisioned as the will to work upon one's body with technology 
to break the ties that hold humanity back from its perceived potential. Many who work in this field in Silicon Valley, echo these ideals of discipline as an ultimate form of secularism. As Nietzsche writes:

God is dead. God remains dead. And we have killed him. How shall we comfort ourselves, the murderers of all murderers? What was holiest and mightiest of all that the world has yet owned has bled to death under our knives: who will wipe this blood off us? What water is there for us to clean ourselves? What festivals of atonement, what sacred games shall we have to invent? Is not the greatness of this deed too great for us? Must we ourselves not become gods simply to appear worthy of it?

The Übermensch is Nietzsche's own answer to this question. It is the individual who has the power to fill the void left from the metaphorical death of God through creativity, will, and sacrifice. Warwick, in famous experiments, had wired his nervous systems to that of his wife's, using implants and electrodes, opening up a new type of interpersonal connection through technological hybridity. He, and his students, are proud to have operated upon their own bodies, to feel these sensory alignments for themselves. It was for them posthuman, but it was simultaneously art practice, extending their imagination into body transformation and visceral connection, with the goal in mind to take humanity forward into something new, and ontologically 'higher.' Embedded then, in this idea of the cyborg post-human is the artist-tyrant, the artist who uses the human body and mind as canvas to draw the future of the post-human person. The spiritual connotations are important, and we will return to them below.

The concept of the artist within cyborgian practice appears in other subtle ways. For example, Warwick and his team at the University of Reading use tattoo artists as technicians for their post-human experiments. For the scientists involved, this is a pragmatic decision. Tattoo artists are experienced in working carefully with the boundaries of the skin, navigating the biology just under the flesh with the presentation of art on its surface. Yet, there is analytical value in recognising that the skills used in making traditional forms of body art are the same as those used in constructing the 'post-human.' The study of tattoos within anthropology raises interesting questions for the analysis of the cyborg. Tattoos are another kind of imbrication between the material form of the body, technology, and art that has captured the imagination of social science. Ethnography on tattoo practice has produced a diverse range of theory. Tattoos have been conceived as forms of self-regulation (Atkinson 2004), practices in autobiography (Oksanen and Turtianen 2005), phenomenological engagement of pain and emotional grounding (Ferreira 2011), commodification of persons (Blanchard 1991), commodities in and of themselves (Kosut 2000), or indeed as devoid of real meaning at all, exemplifying the idea of a Levi-Straussian floating signifier 
(Benson 2000; Sweetman 1999). Given the similarities between this type of body work and that of the cyborg, important questions can be raised within the subdisciplines of material culture studies and the anthropology of the body. Why are these analytics that have been applied to tattoos rarely (if ever?) applied to the cyborg? Why are tattoos not analysed as post-human practice?

It is crucial to note, however, that many of these technologists are also motivated by a desire to help others, through therapies that alleviate suffering, improve medicine, or adapt the human body to address conditions of oppression. Neural implant research, for example, is funded to address cognitive disorder, neurodegenerative diseases, or sensory limitations. Kevin Warwick often highlights to the public how neurostimulator implants might radically improve the symptoms of Parkinson's disease. The effects of using the technology are immediate. The individual's constant muscle tremors, a defining characteristic of Parkinson's disease, are instantaneously relaxed. However, users themselves see the human/tech hybrid as transformative of identity and the self beyond the simple therapeutic effects of the technology (Goddard 2015). Similarly, technology has been designed for neurocognitive enhancement to address memory loss. An artificial hippocampus can assist with long term memory potentiation, storage, and retrieval, promising hope for the families, carers, and sufferers of dementia and Alzheimer's. It is difficult, however, to confine a technology of this nature to therapeutic uses. There are countless contexts in which these technologies raise questions beyond addressing illness.

In a very different context, yet one that still pushes at the secondary impact of human-plus technological interventions, Lockheed Martin - the American global aerospace, defence, security and advanced technologies company has produced lithium bionic tech in the form of its Human Universal Load Carrier, or HULC for short - drawing again on the superhero discourse that accompanies the cyborg in technical demonstrations. As an attachable exoskeleton, HULC allows persons to carry extremely heavy weights long distances without breaking the human body. It was designed for soldiers, but is also repurposed for paraplegics who, through the use of the device attached to the back and legs, are able to walk again.

In contexts of care, the therapeutic possibilities of these technologies put an ethical burden on the professionals and the wider community in terms of striving for the best possible intervention. As Goold and Maslen (2014) pointed out, medical ethics and law are now forced into a position in which they must assess the potential liability and culpability of medical professionals for patient health in light of cognitive enhancement technology that is now available. Technological innovations force new ethics that must balance potential benefits to medical practice against personal agency. When a person's life is at stake in the medical theatre, are surgeons obligated to engage with cognitive enhancement simply because it exists? Particularly in light of the link between cognition and legal definitions of human life, the responsibility to 
preserve cognition by all means possible is an acute obligation. An artificial hippocampus could very well greatly bolster the ability of an individual to retain events, faces, language, and the general experiences of waking life. Yet, for the conscious world of the individual, there is perhaps value in being able to forget (Erden 2013). The philosopher Paul Virilio (2007) has argued that in the invention of each new technology is also contained its failure; so too each new technology, and especially human-plus imbrications, brings with it new ethical burdens and responsibilities. This is all the more true in contexts where the imbrication holds the possibility for reinventing, or surpassing, the very concept of what it means to be human.

\section{The cyborg and transcendence}

We have briefly outlined above how, for the cyborg, ideas of salvation and transcendence are often confused and interwoven in regards to the technological hybrid. It is a complex Icarian landscape, and it is not surprising, then, to see the human/technology hybrid reconstituted through religion. There is, perhaps, some irony as well. As discussed above, in designing a cyborgian identity, Warwick (and others) preface their work by invoking the Ubermensch. It is the articulation of their post-human desire - bringing humanity forward after what they view as the post-enlightenment death of God. It is, then, interesting to see how the post-human is interpreted by some as the desire of their God, and post-humanism as feeling and being with their God. The Mormon Transhumanist Association, for example, is a group of like-minded individuals who believe that to be a disciple of the Gospel of Jesus Christ is to trust in, change toward, and fully immerse our bodies and minds in the role of Christ, to become compassionate creators as exemplified and invited by Jesus. A basic tenet of Mormon transhumanist practice is that 'post-human' technology is not only a secular prerogative but also the practice of transfiguration.

For some, prophecy is not a living proposition, let alone religion or God. They wonder if we've not heard that God is dead, and they're right to wonder [...]. If God is merely a supernatural superlative, he very well may be dead, but positing such as God misses the function of God. God always has been and is at least a post-human projection, an extension and negation of human desire, imagined and expressed within the constraints of human thought, language and action. If we can raise our eyes from the altar of religious and anti-religious dogma, we'll see that the hand raised to finish the dying God is the sign of the oath to the resurrecting God. If we can keep our eyes raised, resisting the carnage below, we'll also see the hand is our own and it holds a blade that's aged and stained. That's when we have a choice, either to repeat the old sacrifices of our ancestors, or finally to make the new sacrifice that they always implied: we can put ourselves on the altar and learn to become Gods. Put differently, the negation 
of one post-human projection always implies another, misrecognized until humanity chooses to become post-humanity.

(Cannon 2014)

God, for members of this group, is not 'dead' in a Nietzschean sense. Rather, God is practiced through technology. Specifically, leaders of the MTA cite the future ability for human cyborgs to be connected to one another, through thought, physical feeling and emotion.

We $[. .$.$] want to make a better world. We can do that through engineering$ and governance, but it's also not enough that we can make a better world. We want to feel it, sometimes powerfully, and more: we want to share our powerful feelings with others in ways that move us together. As engineering and governance are action on science and ethics, religion is action on esthetics.

(Cannon 2014)

The practice of technology here is, in practical terms, similar to Warwick's famous experiments on the nervous system, but the way in which it is imagined is radically different. It holds no residence in evolutionary theory. 'Feeling' what God feels is reimagined as God's prerogative for humanity, and the historical imperative of religion made increasingly possible through science. Connectedness and communication between individuals are not just discursive for the Mormon transhumanists; these constitute an embodied intersubjectivity. The individual post-human being is imagined as the human collective; it is at once both one and multiple. The image of the cyborg is understood through the symbolism of the Mormon church, and specifically the honeybee and the beehive. In Mormon thought, the honeybee (called 'deseret') is conceived as a model of productivity, collective goals, and selfsufficient labour. For the MTA, the post-human figure is likewise understood in these terms. It is the model of living set out by the prophets of Mormon history, and advocated by Brigham Young and his followers as they settled in the American West. As anthropologist Jon Bialecki has pointed out, the MTA is the religious group most in tune with secular humanists, emphasising that God will not deliver people to post-humanism - it is something that God asks people to do for themselves (Bialecki 2017).

Increasingly there are other religious groups exploring constructs of spiritualism through technological embrace and cyborg hybridity. The Christian Transhumanist Association has developed a growing following since its formal 2014 inauguration in Tennessee. Similarly, Buddhist transhumanism is promoted in both Silicon Valley and in spiritual groups in India, portraying the Buddha as a cyborg, and arguing for spiritual awakening through technological advancements. All these movements apply scriptural interpretation as evidence for justifying cyborgian movements as well as ethical and moral authority. 
While some religious groups frame the cyborg as a return to God, many secular transhumanists imagine the cyborg as a future-oriented goal to move humanity away from the old world of gods, binarisms, and power structures. This variety in narrative aspiration is made more complex by another growing group of individuals, who call themselves artists, citizen scientists, and cyborgs. Abandoning the trope of the superhero, they have little or no interest in gods. They envision transhumanism, instead, as a return to nature. Their experiments mirror or expand upon the work on sensory play in academic cybernetic laboratories, but their emphasis on 'connectivity' between themselves, others, and the environment is imagined as a type of restoration of the body - 'regaining' sensory perception lost or deselected in the course of human evolution. For those seeking to 'return' to nature, cyborgian engagement is a reaction to (against) urban life. However, as the sociologist and philosopher of technology Lewis Mumford has written,

The city is a fact in nature, like a cave, a run of mackerel or an ant-heap. But it is also a conscious work of art, and it holds within its communal framework many simpler and more personal forms of art.

(Mumford 1938: 5)

Borrowing Mumford's language, the cyborg is both a fact in nature, and a conscious work of art (Parkhurst 2016). In each case, the aspiration to surpass normative human capacity makes certain kinds of claims about the morphological constitution of the contemporary, twenty-first century body and the properties, affordances, and capacities the person might possess if this body is tactically joined with technological enhancements.

\section{The twenty-first/first-century body}

We are not suggesting that these religious groups versus secular groups are in direct contrast to each other; indeed, the relations between nature and deities is problematic, even within the European intellectual tradition out of which most of these individuals arise. Motivations differ and specific 'types' of post- or transhumanism can be mapped, to varying degrees of success and precision. However, this level of precision often belies the social fact that the individuals within the movement often borrow inspiration (either as positive influence or reactive counterbalance) from other groups using similar (and often fluid) terminology. All these groups (and many others, for which there is not space to discuss) borrow terms such as the cyborg, transhumanism and post-humanism in ambiguous and often interchangeable ways. Our aim in this chapter is not to abandon these terms, especially in their ethnographic usage. Our primary concern is the relationship between human and post-human practices, afforded by human-plus imbrications. We are not denying our subjects their post-humanism. We are suggesting, however, that the narrative of post-humanism is, on an analytical level, 
fundamentally and deeply human. In this regard, the twenty-first century body is synonymous with the first century body. This final section considers the parallels between the promissory technologies of the cybernetic future and those embedded within traditions that have clear lines of continuity going back centuries.

In what is reasonably a radically different context, the Eastern Orthodox Christian religious tradition has passed down from the first few centuries of the common era a set of textiles that have a critical and essential role in the ritual practice of the Eastern Christian faith. Something about fabric - with its ability to fold and flutter, show and shroud, shift and shimmer - allows it to act as a technology of transformation, creating sacred spaces in a variety of contexts (Carroll 2017). As a technology of transformation, textiles (like tattoos and more broadly clothing) are also routinely used cross-culturally to enhance personal capacities. This might be as simple as sportswear designed to make the body more aerodynamic, or undergarments designed to make it less so. This final section examines the enhancement in religious contexts, where the capacity achieved by the technological union of body to fabric is not simply being 'better,' but being 'other.'

In Orthodox Christianity, the priest clothes himself in a series of garments, each with a range of symbolic associations drawing from both ancient Judaism and the imperial custom of the Eastern Roman Empire (for more on this, see Chrysostomos 1981, West 2013, Carroll 2018). When a new priest is ordained, there are three required components: a bishop to pray for and anoint the candidate; a congregation to give their assent to the ordination; and the vestments of office. After a series of ritual prayers and anointing, the candidate is brought to face the congregation. The bishop then gives the newly ordained priest each item of vesture due his new office, and helps him dress, there in the view of the people, who publicly confirm that he is worthy of his new office. The newly made priest is then turned, back to the altar, and helps in the consecration of the Eucharist, thus fulfilling a crucial capacity of his new role.

In Orthodoxy, the priest continues to need the people and the vestments in order to fulfil his priestly office; a priest without a congregation cannot perform the services. Similarly, in order to perform the rite of confession, the priest who hears the confession (including thoughts, concerns, and admission of fault) of a penitent individual must have an epitrachelion to offer ablution (forgiveness). The epitrachelion is a long strip of fabric, shaped like an ox's yoke, that rests over the nape of the priest's neck, and hangs down his front, roughly to his knees. While a priest may listen to the penitent person without the epitrachelion, when it comes time to pray the prayers of forgiveness, the priest must don the epitrachelion, and - usually asking the penitent to kneel - he drapes the long stretch of fabric over the individual's head. With the priest wearing the epitrachelion, and the penitent sheltered underneath it, the prayers of forgiveness are said, and the penitent then leaves having been freed from any burdens they may have had. 
The technological hybrid of priest-plus-vestment is able to do something for the penitent that an ordained priest without vestments cannot do. What is particularly important for our argument here is that this action - namely the forgiveness of sins - is understood to be a more than human capacity. Using the voice of the Old Testament prophet Isaiah, God claims the sole capacity to forgive sins (Isaiah 43:25) and, in the Gospel account of Christ healing a paralytic, the Jewish scribes again affirm that only God can forgive sins (Mark 2:7). This divine ability to forgive sins is then conferred upon the apostles (John 20:23), and through the laying on of hands (i.e., the service of ordination) that ability is passed on to subsequent generations of bishops and priests. The ability of the priest to forgive sins is, however, only a potential ability until he is vested in the epitrachelion. Without the technical apparatus of his office, he is unable to perform the divine act of forgiving sins. Conjoined to the ritual technology of Orthodox priesthood, or 'vested with the grace of the priesthood' (as he says of himself in the liturgy), he is able to perform actions only capable of, the supra-human.

It is also important to note that this kind of transformative capacity of ritual paraphernalia, which renders the human more than human, is not limited to the monotheistic or salvific religions. As Pedersen (2007) has shown in the case of Mongolian shamanism, the kind of engagement with the spirits made possible when clothed in the shamanic costume is so potentially other so as to be a real danger to the human. He argues 'that the shamanic costume affords the shaman with a multiple, extra-human body, which, by inducing a momentary transformation of his or her corporal gestalt, enables the shaman to attain otherwise unattainable points of view' (2007: 142). At the completion of the shamanic ritual, the shaman's assistant must rush to take off the costume (headgear, then robe, then boots), as 'it is considered extremely dangerous to wear the costume without continuing drumming'; once disrobed, 'the shaman slowly becomes herself' (152). During the event, rather than being strictly human, the shaman is a 'knot of knots' - a sort of composite multi-event moment; as Pedersen summarises, 'By donning the costume, then, a Darhad shaman is transformed into the ultimate multinatural entity, as this hyper-surface is believed to transport the shaman to an immanent space of multiplicities' (159, emphasis original).

\section{Discussion}

In the phenomenological tradition within material culture studies, Jean-Pierre Warner (2001) draws upon the insight of Paul Schilder (1923) to help answer the problem of the Kabyle man in his slipper - able to run down a hill quickly, despite the kind of footwear - which confuses Marcel Mauss (1973[1935]). In Warnier's solution, he posits that had Mauss known of Schilder when writing techniques of the body, he would have understood the capacity of the mind, and thereby motor functions, to be extended beyond the body into the attached objects (shoes, walking sticks, etc.) as well as rooms and 
other material environments (such as a basketball court). The relationship between the human and the external technology must be framed in terms of the affordances of the materials at play. This includes both the human body and the specific artefacts being attached to the body in the human-plus imbrication. While this is, as seen in Haraway's work, relevant to the hermeneutic tradition of intellectual scholasticism, it is also driven by the material constitution of the bodies and external things. This 'material hermeneutics' (Ihde 1998) opens up new points of investigation into how human-plus relationships work.

In terms of the hermeneutics of technology, there is also an important distinction to be made between the potentiality and the affordance of a technical object. When something is framed in the language of 'potentiality', it is inscribed with intention and futurity (Taussig et al. 2013) - which are sticky, messy concepts and, as we have written elsewhere, give rise to failure, as the materiality of the artefact will develop in unexpected and unanticipated directions, aborting the process of objectification (Carroll et al. 2017). The affordance of the material (including, importantly, the human flesh) to make certain kinds of sociality possible, is constrained by the historically contingent ways a society knows the material around it (Gibson 1979), but also holds the possibility of shaping society in new ways. As Taussig et al. argue, potentiality and the promissory hope it offers should be both an analytic and an object of study. In a post-phenomenological tradition (Ihde 1993), the discourse around the promise and hype of technology - such as biomedicine, cyborg enhancement or sacerdotal paraphernalia - must be taken along the 'material hermeneutics' (Ihde 1998) of the given technology in how it shapes the knowledge that is knowable. It is in this aspect that the importance of affordances comes to the fore. In the first instance, these affordances are, as can be seen in Ucko's morphological analysis, related to the form and fit of the technology in relation to bodily apparatus and function. However, by looking at the affordances of things in a comparative framework at the level of transformational capacity of technology - be it cyborian transcendence, medical enhancement, or ritual enactment - a different vantage point opens, allowing for new insight into the aspirational drive of humans to become more than human.

As stated above, each body has its own affordances, and these inform and advance social movements independent of meaning that may be attributed to it. The cyborg, as we have outlined, is a complex term, operating in different and often contradictory ways within the aspirational and promissory narratives of scientistic, religious, and academic circles; it offers a range of promises to different individuals depending on the systems of social relations in which those individuals are embedded. Yet, an examination of the cyborg done in terms of the constituent materials and the intentions of transformation shows how the cyborg is also very human. Despite the narratives of 'post' (modern, human, etc.), the twenty-first century body is the same as that of the first. While this is complicated to some degree when we think of partnerships 
and hybridities, such that the affordances of the body are changed (amplified, extended, enhanced) by the affordances of the technology attached to it, the fundamental basis of material engagement is the same. At the level of potentiality, and what it is that these human-plus imbrications are understood to do, the pre- and postmodern human is similarly reaching for something beyond itself. And in this regard, being post-human is inherently human. 